\title{
EFEITOS DO IDEOLÓGICO E DO HISTÓRICO NOS DISCURSOS EM CIRCULAÇÃO
}

\author{
(Effects of ideology and history in discourses in circulation)
}

Caroline M. Schneiders ${ }^{1}$

Universidade Federal da Fronteira Sul - Campus Cerro Largo/RS

Mirela Schröpfer Klein ${ }^{2}$

Universidade Federal de Santa Maria

\begin{abstract}
RESUMO
Refletimos sobre como os discursos em circulação na região das Missões do Rio Grande do Sul produzem uma determinada história e memória, marcadas pelo esquecimento e por relações ideológicas. Partimos dos pressupostos da Análise de Discurso, articulando-a à História das Ideias Linguísticas e nosso objeto de estudo é constituído pelo jornal cultural de circulação regional: Os Nheçuanos, e pelo Portal das Missões, um site institucional da região. Ao compreendermos as determinações históricas que afetam os discursos sobre que circulam nesse contexto, explicitaremos os efeitos da ideologia dominante, bem como da memória discursiva que irrompe no fio discursivo e produzir efeitos de sentido.
\end{abstract}

Palavras-chave: Esquecimentos. Memória. História.

\begin{abstract}
We reflect on how discourses in circulation in the region of the Missions, in Rio Grande do Sul, produce a certain history and memory, marked by forgetfulness and ideological relations. We start from the presuppositions of Discourse Analysis, articulating it to the History of Linguistic Ideas, and our object of study is constituted by the cultural newspaper of regional circulation, Os Nheçuanos, and by the Portal das Missoes, institutional website of the region. By understanding the historical determinations that affect the "discourses about" that circulate in this context, we show the effects of the dominant ideology, as well as the discursive memory that erupts in the discursive thread and produce effects of meaning.
\end{abstract}

Keywords: Forgetfulness. Memory. History.

Recebido em: outubro 2018

Aceito em: maio 2019

DOI: $10.26512 /$ les.v20i1.17349

\footnotetext{
${ }^{1}$ Professora adjunta de Língua Portuguesa e Linguística junto ao Curso de Letras Português e Espanhol. Possui graduação em Letras/Português-Literaturas da Língua Portuguesa pela Universidade Federal de Santa Maria, mestrado e doutorado em Letras - área de concentração: Estudos Linguísticos - pela mesma instituição. Realizou estágio de doutorado sanduíche (Bolsista Capes/PDSE) no Institut des Textes et Manuscrits Modernes (ITEM), pertencente à École Normale Supérieure (ENS/Paris, França). Possui Pós-doutorado (Bolsista DOCFIX-Fapergs) junto ao Laboratório Corpus/Programa de Pós-graduação em Letras da Universidade Federal de Santa Maria. E-mail: caroline.schneiders@uffs.edu.br

${ }^{2}$ Mestranda junto ao Programa de Pós-Graduação em Letras - área de concentração: Estudos Linguísticos. E-mail: mirelask@live.com.
} 


\section{INTRODUÇÃO}

A história para ser retratada baseia-se em discursos que se sobressaem uns aos outros. Esses discursos com maior força de disseminação cultural são chamados de discursos dominantes e, a partir deles, a história tende a se organizar, produzindo o que podemos chamar de uma memória institucionalizada, a qual visa a regular certos sentidos e dizeres (ORLANDI, 2005).

Tendo em vista o modo como os discursos em circulação em determinado contexto sóciohistórico constituem uma história e memória institucionalizadas, cristalizando sentidos, interessa-nos refletir sobre os discursos em circulação na região das Missões do Rio Grande do Sul (RS). Com isso, buscamos explicitar como tais discursos produzem uma determinada história e memória, as quais são marcadas pelo esquecimento e determinadas pelas relações ideológicas que marcaram a história da região das Missões-RS. Esse discurso tem por característica ser de cunho bastante religioso, contendo, algumas vezes, certo fervor católico para defesa dos "invasores" que se instalaram nesse espaço. Como afirma Ruy Nedel em seu livro Esta terra teve dono (2010), esta terra já tinha dono e a história das missões é a de homens em lutas permanentes por sua liberdade.

Toda a história missioneira já existente, seus habitantes, no caso os indígenas, sua cultura e sua língua, quando os estrangeiros começaram suas instalações nestas terras, por vezes é ignorada, esquecida, marginalizada. Os indígenas acabaram sendo tachados como sanguinários e cruéis, e tudo que é falado sobre eles parece conter uma história tendenciosa em prol de um discurso dominante do colonizador.

A partir do dito "Esta terra tem dono", proclamado pelo importante líder indígena Sepé Tiarajú em meio à guerra guaranítica, vários estudos têm surgido buscando uma definição para o dono desta terra. Os indígenas lutaram para defender seus costumes perante à imposição proposta pela Igreja Católica, através do projeto de catequização e das implantações das reduções jesuíticas. No contar e recontar das histórias de um tempo não muito feliz, consideramos que no dito sempre há um não-dito, algo que é silenciado, esquecido, fazendo com que alguns sentidos circulem em detrimento de outros.

Considerando as versões que podemos compreender em torno de um mesmo fato histórico, nosso estudo problematiza, por meio dos discursos sobre que organizam a memória em circulação na região das Missões-RS, os efeitos de sentido que tais discursos produzem. Esses efeitos de sentido, para nós, colocam-se entre a memória cristalizada/institucionalizada sobre a história da região das Missões, a qual está vinculada ao funcionamento de uma ideologia dominante, e a memória discursiva, a qual é marcada pelo esquecimento, fazendo com que novos sentidos irrompam na discursividade. 
Para tanto, mobilizamos, como objeto de estudo, o jornal Os Nheçuanos, jornal cultural de circulação local, vinculado à Associação Cultural Os Nheçuanos ${ }^{3}$, criada em 2009, no município de Roque Gonzales/RS, e o site Portal das Missões ${ }^{4}$, site institucional informativo sobre as MissõesRS. A partir desse objeto, realizamos recortes discursivos, os quais constituem nosso corpus de análise. Para o desenvolvimento da presente pesquisa, filiamo-nos aos pressupostos da Análise de Discurso de linha francesa e das Histórias das Ideias Linguísticas, tal como ambas vem se desenvolvendo no Brasil nos dias atuais.

Assim, tendo em vista o que circula a respeito da história da região das Missões-RS, a história dita oficial, considerando, portanto, os discursos institucionais que contam e circulam sobre a história da Missões, interessa-nos problematizar a questão do silenciamento, dos jogos de forças entre o dito e o não-dito, os quais explicitam os efeitos que os discursos dominantes, ou a ideologia dominante, produzem, cristalizando determinada memória e história e silenciando outras.

\section{DisCURSO, SUJEITO E IDEOLOGIA: QUESTÕES INICIAIS}

O desenvolvimento desta reflexão ancora-se nos pressupostos teóricos e metodológicos da Análise de Discurso (AD) de linha pecheuxtiana em articulação com a História das Ideias Linguísticas (HIL), mobilizando em especial as noções de discurso, história, memória, esquecimento e silenciamento. Tomando como base tais estudos, compreendemos o discurso como um objeto linguístico, histórico e ideológico. Trata-se de "um objeto sócio histórico em que o linguístico intervém como pressuposto" (ORLANDI, 2015, p. 14).

Ao contrário do que muitas vezes se pensa, para a $\mathrm{AD}$, o discurso vai muito além da transmissão de informações, é considerado efeito de sentidos entre locutores (PÊCHEUX, 2014). Ele torna-se, pois, o lugar onde o indivíduo, através da apropriação da língua, é interpelado pela ideologia e irá se constituir como sujeito na história. Ainda, o discurso pode ser entendido como “funcionamento da linguagem que põe em relação sujeitos e sentidos afetados pela língua e pela história” (ORLANDI, 2015, p. 20).

Partindo disso, "procura-se compreender a língua fazendo sentido, enquanto trabalho simbólico, parte do trabalho social geral, constitutivo do homem e da sua história" (ORLANDI, 2015, p. 20). Para a $\mathrm{AD}$, não há discurso sem sujeito e sujeito sem ideologia. O sujeito, para a $\mathrm{AD}$, é

\footnotetext{
${ }^{3}$ A Associação Cultural Os Nheçuanos surgiu em 2009 e tomou forma a partir do Manifesto Nheçuano, encontro cultural que "reafirmou a necessidade de revisão histórica sobre ocupação do território guarani e resistência do cacique Nheçu" (OS NHEÇUANOS, n-1, p.5, 2009). Constituiu-se pela luta de defesa da causa guarani e deu seu grande líder Nheçu e lutam pela revisão definitiva dos fatos que marcaram a ocupação deste território pelo homem branco, na primeira metade do século XVII (informações retiradas da primeira edição do jornal Os Nheçuanos).

${ }^{4}$ Site: http://www.portaldasmissoes.com.br.
} 
constituído através da interpelação ideológica. O sujeito "é posição entre outras, subjetivando-se na medida mesmo em que se projeta de sua situação (lugar) no mundo para sua posição no discurso" (ORLANDI, 2005, p. 99).

O sujeito vai identificar-se com determinado domínio de saber $^{5}$, inscrevendo-se em uma determinada formação discursiva (FD), ou seja, enunciará sempre a partir de uma posição-sujeito ${ }^{6}$. Deste modo, a posição-sujeito se constitui por aquilo que pode e deve, ou não, ser dito em determinada situação/contexto, inscrevendo-se em uma FD em específico (INDURSKY, 2005).

Os discursos que circulam na região das Missões-RS tratam mais especificamente da visão dos jesuítas, os quais, para nós, vinculam-se ao funcionamento da ideologia dominante da época das reduções. Ou seja, esse funcionamento permitiu a constituição e a circulação de um discurso dominante $^{7}$. Através desse discurso dominante, naturalizou-se uma memória coletiva, fixando certos saberes e permitindo a constituição de uma FD em torno da história das Missões que é marcada por uma ideologia religiosa, vinculada aos jesuítas.

A FD, tal como é definida por Courtine (2009), é um sistema de dispersão. Esse sistema trataria de definir os tipos de enunciação, conceitos, escolhas temáticas, uma regularidade do sujeito. A FD, como destaca Pêcheux (2014), é o que determina o que pode e deve, ou não, ser dito e está relacionada às formações ideológicas. Assim, os sentidos estão em jogo no processo sócio-histórico no qual palavras/expressões são reproduzidas.

A FD tem o importante papel de projetar na linguagem a formação ideológica do sujeito. Como apontado por Indursky (2013a), a FD na qual o sujeito se inscreve para a produção de seu discurso implica a retomada de uma memória que foi regularizada, no regime da repetibilidade, que se conecta a já-ditos anteriores e exteriores a ela mesmo.

No nosso estudo, analisando os discursos sobre as Missões, observamos uma identificação com uma FD religiosa, marcada, em especial, nos discursos que circulam a história e a memória institucionalizadas das Missões-RS. Assim, compreendemos que o sujeito do discurso enuncia a partir

\footnotetext{
${ }^{5}$ A identificação discursiva do sujeito se dará através de sua Formação Discursiva, que, como destaca Pêcheux, é "aquilo que numa formação ideológica dada, isto é, a partir de uma posição dada numa conjuntura dada [...] determina o que se pode e deve ser dito" (PÊCHEUX, 2014, p. 147).

${ }^{6}$ Conforme Pêcheux (2014), o sujeito pode identificar-se de modos diferentes frente à FD. Isso refere-se aos três modos de subjetivação proposto pelo autor: identificação plena (do sujeito do discurso com a forma-sujeito da FD), contraidentificação (forma de resistência à forma-sujeito e ao domínio de saberes que ela organiza) e desidentificação (o sujeito desidentifica-se de uma FD e de sua forma-sujeito e desloca sua identificação para outra FD e sua respectiva forma-sujeito) (INDURSKY, 2005).

${ }^{7} \mathrm{O}$ discurso visto como dominante sobre a região das Missões trata da visão jesuítica estabelecida posterior à declaração das Ruínas de São Miguel das Missões como patrimônio histórico da humanidade. Isso ocorre visto que a história retratada sobre as ruínas de São Miguel conta sobre a tarefa humanitária estabelecida aos jesuítas. Há uma história menos valorada, a da cultura e língua indígena, sendo marginalizada, vista como errada aos olhos de quem fala sobre.
} 
dessa posição-sujeito. Esta posição-sujeito explicita a posição ideológica adotada e, entendendo esta determinação, podemos compreender a história institucionalizada na região das Missões.

Como todos os fatores discursivos são interpelados pela ideologia, esta, segundo Althusser (1974, p. 69), pode ser vista como “o sistema das ideias, das representações, que domina o espírito de um homem ou de um grupo social", ou seja, a ideologia rege o modelo de pensamento de um sujeito ou de um grupo de sujeitos. A teoria da ideologia, para o autor, apresenta-se como uma formação social, nos modos de produção combinados nas formações sociais e da história das lutas de classe.

Será assim uma representação da relação imaginária dos indivíduos com as suas condições de existência. Em nosso caso, para que o processo de catequização acontecesse de maneira a extinguir a religião indígena, foi preciso que a Igreja Católica impusesse uma ideologia dominante, a qual, para nós, é entendida enquanto um dos aparelhos ideológicos do estado, conforme Althusser (1974). Qual seria então a relação entre a Igreja e esse processo de colonização, retratado, quase sempre, como pacífico? A questão é bastante clara e diz respeito à dominação da religião católica. Essa tentativa de dominação ocorre através da imposição das crenças religiosas, apagando/silenciando todas as outras que se opõem a isto e as retratando como "coisas do diabo", o que será observado posteriormente na análise. Por isso, a sua relevância aos discursos dominantes que circulam sobre a região das MissõesRS.

Nesse sentido, a ideologia surge, então, como "mecanismo estruturante do processo de significação. [...] A ideologia se liga inextricavelmente à interpretação, enquanto fato fundamental que atesta a relação da história com a língua" (ORLANDI, 2015, p. 94). A ideologia afeta o discurso assim como o interdiscurso, pois é este que regionaliza os saberes da FD, delimitando o que pode e deve, ou não, ser dito em determinadas condições de produção. É o interdiscurso que faz com que o discurso produza sentidos, ancorando-se em dizeres já-ditos. Isto é, faz com que o discurso seja afetado pela exterioridade, seja dotado de uma historicidade que o constitui.

Para Orlandi (2003, p. 13), “todo dizer é já gesto de interpretação, posição face a memória. Para significar, nossas palavras já fazem sentido, se produzem em uma memória significativa, para que possam ser interpretadas". Isso indica que nem sempre podemos afirmar que o discurso está totalmente dito em suas palavras, o que não significar dizer que nos interessa o que está implícito ao discurso, mas, sim, o fato de que no dito sempre há um não-dito, efeito de um silêncio constitutivo, indicando que o sentido nunca é único, o mesmo sempre pode ser outro.

Tendo em vista nosso objetivo, o qual é o de analisar os discursos sobre que circulam em torno da história da região das Missões-RS, consideramos tais questões que afetam e determinam a constituição do discurso fundamentais para compreendermos o processo discursivo do discurso 
tomado, por nós, como objeto de análise. Diante disso, na sequência, discorremos sobre alguns conceitos centrais para essa reflexão.

\subsection{Efeitos do silêncio: entre a memória e o esquecimento}

Para este trabalho, é mobilizado o conceito de silêncio tal como define Orlandi (2007), o qual é constitutivo de todo discurso, pois permite observar quais sentidos e dizeres são postos em circulação e/ou silenciados. Assim, o silêncio

É a "respiração" (o fôlego) da significação; um lugar de recuo necessário para que se possa significar, para que o sentido faça sentido. Reduto do possível, do múltiplo, o silêncio abre espaço para o que não é "um", para o que permite o movimento do sujeito (ORLANDI, 2007, p. 13).

Para a instância do discurso, o silêncio constitui-se como indicador do que funciona entre as palavras, onde "todo discurso já é uma fala que fala com outras palavras, através de outras palavras" (ORLANDI, 2007, p. 15). O silêncio, para o discurso, é o não-dito considerado como significante. Ele não se encontra disponível à visibilidade e, sendo impossível observá-lo, ele torna visível, na verdade, a significação.

Conforme Orlandi (2007, p. 23), “o silêncio, mediando as relações entre linguagem, mundo e pensamento, resiste à pressão de controle exercida pela urgência da linguagem e significa de outras e muitas maneiras". O silêncio não pode ser visto nas entrelinhas, não aborda um significado escondido, apenas faz parte do não-dito. O silêncio vai também apresentar-se para o discurso como fundante, ele tem primazia sobre as palavras, pois aparece na ordem do discurso a nível de matéria. $\mathrm{Na}$ perspectiva assumida em $\mathrm{AD}$, “o silêncio não fala. O silêncio é. Ele significa. Ou melhor: no silêncio, o sentido ê" (ORLANDI, 2007, p. 31).

Assim sendo, o silêncio, para nós, significa, está na constituição dos dizeres e dos sentidos. No momento em que determinados discursos circulam, outros são silenciados, como é o caso dos discursos em torno da história das Missões-RS. No momento que esses discursos são silenciados, apresenta-se o que podemos chamar de política de sentido do silenciamento e é nessa transição de discursos silenciados e dos discursos dominantes que se apresenta a memória discursiva.

O silêncio fundante, considerado como o real da significação, diferencia-se da política do silêncio, portanto "a política do silêncio produz um recorte entre o que se diz e o que não se diz, enquanto o silêncio fundador não estabelece nenhuma divisão: ele significa em (por) si mesmo" (ORLANDI, 2007, p. 73). 
A questão do silêncio torna-se importante para compreendermos os sentidos, uma vez que no dito há sempre um não-dito. Esse funcionamento coloca em jogo a memória discursiva, a qual é estruturada pelo esquecimento. A memória discursiva “é trabalhada pela noção de interdiscurso: algo fala antes, em outro lugar e independentemente [...] É o já dito que constitui todo dizer" (ORLANDI, 2010, p. 21). A memória discursiva é constituída pelo esquecimento, logo "quando enunciamos há essa estratificação de formulações já feitas que presidem nossa formulação e formam o eixo de constituição do nosso dizer [...] são formulações já feitas e esquecidas” (ORLANDI, 2010, p. 21).

A memória discursiva ou interdiscurso diz respeito ao fato de que todo dizer está ancorado em outros dizeres, isto é, em "um dizer já dito e esquecido que o constitui em sua memória" (ORLANDI, 2010, p.22). Ela vai estar situada no campo não da repetição, mas da regularização de sentidos, situando-se entre o histórico e o linguístico (SCHERER; TASCHETTO, 2005). Além disso, entendemos como a memória discursiva que afeta diretamente a compreensão dos discursos sobre que circulam na região das Missões-RS funciona como um operador de memória social.

Lembrando, como destacou Pêcheux (2015, p. 44), “a memória deve ser entendida aqui não no sentido diretamente psicologista da "memória individual, mas nos sentidos entrecruzados da memória mítica, da memória social inscrita em práticas, e da memória construída do historiador”. A memória não será plana e muitas vezes nem visível, será um espaço móvel de disjunção, de deslocamento e de retomada. No caso da memória discursiva, vale lembrar que "a noção de memória discursiva concerne à existência histórica do enunciado no seio de práticas discursivas regradas pelos aparelhos ideológicos" (GRIGOLETTO, 2003, p. 55), ou seja, toda memória está vinculada à interpelação ideológica sofrida pelo sujeito.

Quando tratamos da memória discursiva afetando a constituição do discurso, devemos igualmente considerar que há uma memória institucionalizada a qual ancora e institucionaliza os dizeres e os sentidos, como é o caso na região das Missões-RS. A memória institucionalizada "acumula e visa a estabilizar sentidos, contrapondo-se à memória vinculada ao interdiscurso" (SCHNEIDERS, 2014, p. 106). Esta memória está ligada aos efeitos produzidos pelo arquivo. O arquivo, por sua vez, caracteriza-se por apresentar o que deve ou não ser dito, constituído por um efeito de fechamento. É, a partir desta memória institucionalizada, que os discursos sobre a região das Missões aparecerão, estabilizando sentidos e apagando/silenciando discursos outros, ressoando nos dizeres e nas versões contadas sobre esse contexto sócio-histórico.

\subsection{Discurso de e discurso sobre a região das Missões-RS}


Como o objetivo central desse estudo é analisar os discursos sobre que circulam em torno da história da região das Missões-RS e produzem uma memória institucionalizada, é preciso destacar aquilo que entendemos por discurso sobre e discurso de. $\mathrm{O}$ discurso sobre se constitui a partir do discurso $d e$, caracterizando-se pela rememoração, a qual "ocorre na dimensão não linear do dizer e ocupa o espaço do já dito e do significado antes” (VENTURINI, 2009, p.73). Assim, o discurso de é o discurso ao qual os sujeitos filiam seu dizer, funcionando como um discurso fundador que permite a outros discursos se constituírem, "a partir disso, podemos compreender a historicidade dos processos discursivos e o modo como estão instituídos em relação a outro(s) discurso(s), possibilitando a configuração de discursos sobre, que, por sua vez, tomam como referência o discurso $d e$ "(SCHNEIDERS, 2014, p. 79).

Para dar conta do funcionamento discursivo, o discurso sobre sustentar-se-á na memória histórica devido aos esquecimentos que ocorrem no nível da enunciação e do inconsciente (VENTURINI, 2009). Esse discurso, então, "se funda em outros discursos que constituem a sua memória, a forma de referenciar o dito" (VENTURINI, 2009, p. 77).

O discurso sobre tem como primeiro efeito a aparente estabilidade, onde o sujeito acredita poder realizar o apagamento seletivo da memória histórica, dominando esta materialidade através de sua formação discursiva (FD). Esse apagamento seletivo aparece na constituição do discurso sobre que circula na região das Missões: apagar o sofrimento indígena e romantizar a catequização e dominação cultural e linguística, rememorando os jesuítas como homens que tentavam apenas contribuir para o bem, esquecendo-se do que foi perdido, a cultura e a língua indígena, junto ao que foi silenciado/apagado posteriormente.

Mesmo trabalhando com questões históricas, o que nos interessa é a historicidade do texto, o que não se relaciona diretamente com a noção de história. A historicidade pode ser definida como "o seu acontecimento como discurso, seu funcionamento, o trabalho dos sentidos nele" (ORLANDI, 2010, p. 22). Há uma ligação entre a história (que circula) e a historicidade, ela "não é nem direta, nem automática, nem de causa e efeito, e nem se dá termo a termo" (ORLANDI, 2010, p. 23), se dá como uma relação complexa e que para ser trabalhada é preciso a compreensão do funcionamento do discurso.

Assim sendo, para compreendermos o processo discursivo, devemos conseguir estabelecer relações entre a historicidade do discurso e os sentidos, sendo isso que objetivamos ao analisar discursos sobre, mais especificamente, discursos sobre a região das Missões-RS. 


\section{UM OLHAR SOBRE O CORPUS: GESTOS DE INTEPRETAÇÃO POSSÍVEIS}

Para o desenvolvimento analítico dessa reflexão, mobilizamos, como objeto de análise, discursos sobre a região das Missões que estão em circulação. Inicialmente, mobilizamos o jornal Os Nheçuanos e o site Portal das Missões. A partir desse objeto, realizamos recortes discursivos (RDs) constituindo o nosso corpus de análise. Como critério de seleção para os recortes discursivos, partimos das regularidades discursivas observadas no que se refere à determinação ideológica e ao silenciamento, seja este histórico, linguístico e/ou cultural.

O jornal cultural Os Nheçuanos apresenta-se em forma impressa, procurando destacar, através do conteúdo publicado, a importância do cacique Nheçu, um líder indígena que atuou junto ao grupo de indígenas que não permaneceu vinculado às reduções, e das versões outras, as quais também são possíveis sobre a história das Missões-RS. O jornal tornou-se nosso objeto de interesse por trazer em sua capa o seguinte enunciado em guarani: “(...) Nheçu, líder indígena Guarani, defensor de seu povo, sua cultura e sua terra, pioneiro na resistência aos conquistadores, no século XVII, na atual região das Missões (...)". Esse enunciado já nos indica alguns sentidos sobre a história e versão que será retratada e nos chamou a atenção por contrapor com o que está veiculado na história dita oficial, que traz apenas o indígena Sepé Tiaraju como sendo o grande líder desta história. A partir disso, questionamo-nos sobre as outras versões dessa história, atribuindo importância aos indígenas e não somente aos jesuítas.

Assim, o jornal é composto por informes e reportagens históricas sobre a região das MissõesRS. Traz também, em suas páginas, informações sobre os mais variados assuntos do Rio Grande do Sul e do Brasil. Conta ainda com uma seção para abordar a cultura Guarani, trazendo questões linguísticas. Considerando esse objeto e nosso objetivo, realizamos recortes discursivos retirados de 5 notícias.

Essas notícias têm por objetivo também informar aos leitores a versão menos idealizada do ocorrido em 1628, trazendo para o público leitor a versão indígena dos fatos e colocando o cacique Nheçu como um herói, ao lado de índios como Sepé Tiaraju. Isso ocorre pelo simples fato de que o cacique Nheçu foi deixado à sombra de acontecimentos históricos, pois os fatos são relatados a partir de um outro viés, minimizando alguns acontecimentos e dando maior relevância a outros. As notícias desse cunho são encontradas com maior assiduidade nas primeiras edições do jornal, sendo possível localizar dentro de uma única edição de 5 a 6 notícias sobre os ocorridos em 1628 e a luta de Nheçu. Com o passar das edições, a ocorrência destas notícias diminui, dando lugar a outros conteúdos culturais divulgados pelo jornal. 
Com relação ao site Portal das Missões, trata-se do portal oficial da região das Missões que relata as versões consideradas como oficiais dessa história. Essas versões trazidas pelo portal fazem parte da memória institucionalizada na região, abordando e dando relevância a alguns fatos, e silenciando outros discursos sobre. Deste objeto foram mobilizados recortes discursivos observados em 5 informes, sendo esses parte da história, tida como oficial, e retratam a história do assassinato dos santos padres no Santuário Assunção do Ijuí (ou Santuário João de Castilhos).

O site tem como principal objetivo informar a seus visitantes sobre turismo, atrativos, hospedagem, gastronomia, locomoção, comércio, serviços e história da região das Missões. Podemos encontrar no site informes culturais, notícias, imagens e vídeos. Dentro da área de cultura, encontramse os informes históricos (como os mobilizados para análise) para que o visitante conheça a história ${ }^{8}$ da região missioneira. Essas reportagens retratam como sanguinário o modo como os índios teriam assassinados os padres jesuítas, deixando um imaginário de crueldade não só para os leitores, como também reproduzem uma determinada versão sobre os fatos.

Tendo em vista nosso objeto de estudo e a perspectiva teórica adotada, cabe pontuar que não trabalhamos com uma metodologia pronta e fechada. Pelo fato de a AD se constituir como uma disciplina de entremeio, a metodologia utilizada para os estudos em Análise de Discurso se constrói através de um movimento pendular. Esse movimento pendular, ou de vai-vém, fazendo com que o analista, através do corpus construído produza um efeito transitório. Dizer isso, "significa dizer que o movimento pendular pode ter início na teoria ou na análise, sem prejuízo nenhum ao processo em si e quanto aos resultados da análise, podemos dizer que dependem de uma série de elementos (teórico-metodológicos) mobilizados no decorrer do trabalho analítico" (PETRI, 2013, p. 42), ou seja, a questão metodológica pode iniciar tanto a partir de seu referencial teórico quanto partindo da construção de seu corpus de análise.

\subsection{Gestos de interpretação}

Tomando por base o dispositivo teórico e analítico do presente estudo, propomos lançar gestos de interpretação sobre o corpus de análise, o qual é constituído por recortes discursivos. O corpus mobilizado, como já destacado no item anterior, consiste em 5 informes retirados do Portal

\footnotetext{
${ }^{8}$ Vale ressaltar que, quando falamos de história, automaticamente vem à memória e à história já institucionalizada na região e tida como oficial. Tratando do Portal das Missões, não podemos deixar de lembrar que é um site governamental, ou seja, ele abordará as questões históricas a partir da memória institucionalizada, mesmo que isso custe alguns detalhes importantes para a compreensão, por exemplo, a pergunta de "por que os índios se rebelaram?", não terá uma resposta clara.
} 
das Missões e em 5 notícias retiradas do jornal Os Nheçuanos. Para a análise, foram selecionados pequenos excertos ${ }^{9}$, considerando os nossos objetivos.

A inquietação inicial para desenvolvermos nossos gestos de análise partiu do fato de os informes, retirados do Portal das Missões, trazerem, em seu conteúdo, um viés que retrata como sanguinário e pecaminoso os modos como os indígenas teriam utilizado para a defesa de seu povo, de seus costumes, sua religião e até mesmo sua língua.

Verificamos, numa visão geral sobre o objeto em análise, a existência de interpretações distintas acerca da história e dos discursos em circulação sobre as Missões-RS, as quais podem ser compreendidas já pelo título de uma das notícias presentes na edição 15 do jornal (recorte R1N1) "Padre Roque e Nheçu - Uma outra história" (TAVARES, 2012), o que nos leva a refletir sobre qual seria esta outra história e por que seria necessário contar a história através de um outro viés. Neste mesmo artigo, presente no subtítulo, tem-se (recorte R2N1): "Relatos da invasão das terras dos Guarani no sul do Brasil” (grifo nosso), em que chama atenção a escolha do termo invasão para definir a chegada e instalação dos jesuítas e a construção das reduções, trazendo fortemente a ideia de ocupação (não pacífica) de espaço que já possui dono.

A escolha linguística do termo invasão já traz a ideia institucionalizada do termo. O campo semântico adotado para a escolha do termo remete à ideia de ilegalidade da palavra, onde, ao escolher usá-la, o leitor é (inconscientemente) induzido a instituir uma rede de memórias ao ler o subtítulo, como destacado por Indursky (2013b).

Nos recortes dos informes, é perceptível a indução da contrariedade vista no Portal das Missões. O termo brutalidade, também uma escolha linguística, destaca estas várias versões e interpretações impostas sob um mesmo fato:

R1I1: "No interior desta capela se encontra uma escultura em madeira maciça do mártir missioneiro João de Castilhos, uma verdadeira obra de arte. Hoje este local sagrado por registrar este ato histórico que influenciou a cultura gaúcha, dividindo por sua brutalidade a vinda da Companhia de Jesus em primeiro e segundo período Jesuítico é visitado por turistas, excursões e romeiros religiosos." (Disponível em: http://www.portaldasmissoes.com.br/site/view/id/1619/capela-dosantuario-de-sao-joao-de-castilhos.html. Acesso em 30/03/2018, grifo nosso)

As escolhas linguísticas realizadas para a construção dos recortes ajudam a refletir o modo sobre como a história é retratada. Sempre há o viés do colonizador (tratado com brutalidade) e do colonizado (que teve suas terras invadidas) e, é através deste viés, que podemos observar, como

\footnotetext{
${ }^{9}$ Por questões metodológicas, no decorrer da análise, os recortes serão identificados através da sigla R1I1 (recorte 1 do informe 1, por exemplo), referindo-se aos informes, ou R1N1 (recorte 1 da notícia 1, por exemplo), referindo-se às notícias, seguindo uma sequência numérica.
} 
destaca Indursky (2013b) os lugares discursivos. Estes lugares discursivos indicam o modo como o discurso se inscreve em determinada FD. Pêcheux (2014) afirma que

o sentido de uma palavra, de uma expressão, de uma proposição etc., não existe "em si mesmo" (isto é, em sua relação transparente com a literalidade do significante), mas, ao contrário é determinado pelas posições ideológicas que estão em jogo no processo sócio-histórico no qual as palavras, expressões e proposições são produzidas (isto é, reproduzidas). Poderíamos resumir essa tese dizendo: as palavras, expressões, proposições etc., mudam de sentido segundo as posições sustentadas por aqueles que as empregam, o que quer dizer que elas adquirem seu sentido em referência a essas posições, isto é, em referência às formações ideológicas [...] nas quais essas pessoas se inscrevem (PÊCHEUX, 2014, p. 146-147, grifos do autor).

Assim, a escolha dos termos invasão e brutalidade, apresentados nos recortes R2N1 e R1I1, estão determinados pelo processo sócio-histórico e pela posição ideológica de quem os enunciou.

Os recortes retirados do jornal relatam os fatos ocorridos no tempo em que o indígena Nheçu ainda reinava sobre as terras que hoje compreendem os municípios de Roque Gonzales/RS e de Pirapó/RS. Com esses recortes, buscamos compreender como a história e os sujeitos, interpelados pela ideologia, contam os mesmos fatos de maneiras tão diferenciadas.

Podemos perceber que, nos discursos sobre que circulam na região das Missões, há um cunho religioso, onde se observa o funcionamento da ideologia dominante dos jesuítas. Isso pode ser observado nas histórias repassadas entre gerações e também no site Portal das Missões, como entendemos pelo recorte R2I2, retirado do informe "Santo Padre Roque Gonzales - Mártir Missioneiro", presente no Portal das Missões: "Depois de celebrar a missa com os índios, padre Roque estava levantando um pequeno campanário na capela recém-construída, quando índios rebeldes, a mando do invejoso e feiticeiro "Nheçu”, atacaram aquela e a vizinha redução" (Disponível em: http://www.portaldasmissoes.com.br/site/view/id/1235/santo-padre-roque-gonzales---martirjesuita-missio.html. Acesso em 17/04/2018).

Os recortes realizados no jornal Os Nheçuanos mostram-nos exatamente o contrário, como podemos compreender pela passagem abaixo:

R3N1: “A trágica morte de Roque e dos outros padres não representou nada mais do que a dolorosa resistência dos índios guarani contra a destruição do seu mundo. A igreja torna os padres seus mártires e erguem santuários que perduram até hoje. Mas aos índios, nada é reservado, a não ser o esquecimento." (TAVARES, Edição 15,2012 , grifo nosso)

A cultuação a uma cultura totalmente diferente da disseminada, rica em diversidade e atrelada a diversas formas de culto a deuses distintos, é deixada de lado das histórias, tidas como oficiais. Atrelado a este viés ao qual a história do povo indígena foi esquecida nos discursos que 
circulam sobre a história da região das Missões, trazemos o recorte R3I3, do site Portal das Missões o qual destaca:

\begin{abstract}
"Afonso Rodrigues, junto com os demais martirizados, foi beatificado pelo papa Pio XI em 28 de janeiro de 1934, e canonizado pelo papa João Paulo II em 16 de maio de 1988. Em Caaró [...] foi erguido um santuário em honra aos jesuítas mártires [...]"

(Disponível em: http://www.portaldasmissoes.com.br/site/view/id/1746/santopadre-afonso-rodrigues---martir-jesuita-miss.html. Acesso em 30/03/2018, grifo nosso).
\end{abstract}

Por conta de o povo indígena não possuir visibilidade diante da história tida como oficial é que se institucionalizam discursos sobre as suas lutas, retratando-as como um simples ato falho de compreensão humana, um erro, como destacado no recorte R4I4, retirado do site Portal das Missões

"Foi torturado e morto tragicamente [...] Santo João de Castilho, foi vítima da incompreensão humana. $O$ cacique Nheçu, acreditava eliminando os padres afastaria a ameaça dos bandeirantes, mandou matar a todos para assim afugentar a ameaça dos caçadores de índios" (Disponível em: http://www.portaldasmissoes.com.br/site/view/id/1770/santo-padre-joao-decastilho-martir-jesuita-missio.html. Acesso em 30/03/2018, grifo nosso)

A partir dos grifos, percebemos que os jesuítas (os mesmos que são martirizados, beatificados e canonizados pela Igreja) são retratados, a partir deste viés da história, como santos e sua morte como uma injustiça. Matar é injustificável, porém, no contexto analisado, os indígenas estavam, a partir de suas crenças, tentando manter intactos os seus costumes, o seu modo de vida, a sua língua e a sua religião.

No trabalho observado nas escolas da região com a matéria de História, com enfoque na história missioneira ${ }^{10}$, o povo indígena é retratado como sanguinário, quando estavam tentando defender seu povo da dominação cultural, religiosa e linguística que os jesuítas impunham. No recorte R4N1, referente ao artigo "Padre Roque e Nheçu - uma outra história", presente no jornal Os Nheçuanos, é abordada a seguinte questão para as lutas travadas: "O motivo não foi outro que a completa incapacidade de cada um deles em compreender que as gentes que ali viviam não precisam de novos deuses" (TAVARES, Edição 15, 2012, grifo nosso), o que é contraposto no informe publicado no Portal das Missões com mensagens religiosas, retratando os missionários jesuítas e as reduções como idealizadores da eliminação do mal, referindo-se à cultura indígena.

\footnotetext{
${ }^{10} \mathrm{O}$ trabalho desenvolvido acerca da história da região das Missões na matéria escolar de História, ajudará a contribuir para essa cristalização de sentidos de que os jesuítas vieram para a região a fim de salvar os povos indígenas de seus pecados. Maiores informações podem ser encontradas no artigo "Análise das missões jesuíticas do Rio Grande do Sul nos livros didáticos" (VALENZUELLA, 2013) de Tainá Severo Valenzuella, publicado na Revista Latino-Americana de História, v. 2, n-6, p. 311-330, agosto/2013.
} 
Na edição 1 do jornal, com a matéria “A história é prisioneira da política”, Nedel (2009), destacará, como observamos pelo recorte R5N2, que "A história das Missões Jesuíticas continua prisioneira da política até mesmo no angustiado anseio pela verdade histórica porque, mesmo então, tende a ser escrita pelo lado e ótica do vencedor" (NEDEL, Edição 1, 2009, grifo nosso) e conclui, como observamos:

R6N3: "Na história das Missões Jesuíticas o principal agente desta história - o índio, o vencido - não a escreveu; esta é uma razão forte, quase imperiosa, para que a literatura aumente seu espaço neste conteúdo histórico, porquanto só ela pode e tem o direito de interpretar os sentimentos do indivíduo ou grupo de individualidades (sociedade) dentro deste consenso triste, trágico e genocida, mas também impressionante e fantástico." (NEDEL, Edição 1, 2009, grifo nosso).

A partir dos grifos, podemos perceber uma explanação dessa outra realidade histórica, silenciada por questões políticas e ideológicas, onde apresenta-se a ideia de vencedor e vencido, dando ênfase à batalha de culturas (deixando de lado a guerra física). Ao destacar o trecho "o principal agente desta história" 11 coloca-se em evidência que os ocorridos só de fato aconteceram por conta da luta indígena pela preservação de sua cultura, o que pode ser observado também no recorte R7N3, destacado do artigo “Opção religiosa de Nheçu: pajé ou padre (jesuíta)?”, presente na edição 5 do jornal, o qual diz: "o intuito era fazer desaparecer a religião antiga e impor a sua, a dos europeus, brancos e católicos" (CATEN, Edição 5, 2010, grifo nosso) explicitando o fato de toda e qualquer luta travada desde a chegada dos jesuítas não foi contra os jesuítas de fato, mas sim contra a doutrinação imposta por eles aos indígenas.

Retomando o termo verdade histórica, faz-se pensar qual verdade plena apresentaria a história? Existiria de fato uma verdade plena? Segundo Paul Henry (2014), a história não representaria mais do que o lugar ou o espaço da combinação, da articulação, da complementariedade de processos e mecanismos por si mesmos a-históricos.

Esta imposição e funcionamento postos pela Igreja Católica para uma dominação cultural e religiosa dos indígenas, vincula-se, para nós, ao que Althusser (1974) propôs sobre os Aparelhos Ideológicos do Estado (AIE) e os Aparelhos Repressivos do Estado. Este segundo funciona no limite da repressão e só existe devido à pluralidade de aparelhos ideológicos do Estado. Esta repressão

\footnotetext{
${ }^{11}$ Cabe aqui destacar que a história é sempre contada através de um viés, sempre terá dois lados, normalmente abordada pelo viés do vencedor. No caso da luta travada entre índios e jesuítas, fica claro quem foi o vencedor. Vários historiadores destacam as lutas (para o trabalho destacamos as palavras de Ruy Nedel, missioneiro), mas é perceptível o quanto os povos indígenas perderam ao tentarem lutar pela sua cultura, religião e costumes ao serem dizimados, posteriormente, na guerra guaranítica. O trecho "o principal agente desta história” fará referência aos indígenas, sempre esquecidos, quando contamos a história através do viés vencedor.
} 
funciona pela busca de um corpo único que não é imediatamente visível. É possível observar esta dominação cultural a partir do recorte abaixo, onde é colocada a questão de que

R8N4: "a história foi redigida ao sabor dos colonizadores, os conceitos de justiça totalmente escamoteados, os reinos usaram a cruz onde a espada e o arcabuz não tinham força para promover a conquista. Os missionários podiam ter boas intenções, mas a estrutura do poder decidia os fins" (SAKAMOTO, Edição 32, 2017, grifo nosso).

Os Aparelhos Ideológicos de Estado são designados como um certo número de realidades sob a forma de instituições distintas e especializadas. Consistem no AIE Religioso (o sistema das diferentes igrejas); o AIE escolar (sistema de diferentes escolas, tanto públicas quanto particulares); o AIE familiar; o AIE jurídico, o AIE político (o sistema político ao qual fazem parte os diferentes partidos); o AIE sindical, o AIE da informação (imprensa, rádio, televisão, etc.) e o AIE cultural (Letras, Belas Artes, desportos etc.). O que distingue os AIE do Aparelho Repressivo de Estado é que este segundo funciona pela violência enquanto os AIE funcionam pela ideologia (ALTHUSSER, 1974).

No caso específico das reduções jesuíticas, a Igreja assumirá sua posição tanto como Aparelho Ideológico do Estado, através do seu sistema e de sua imposição ideológica, como Aparelho Repressivo do Estado, fazendo uso da violência para a repressão.

O Aparelho (repressivo) de estado funciona de uma maneira massivamente prevalente pela repressão (inclusive física) embora funcione secundariamente pela ideologia (não há aparelho puramente repressivo) [...] os Aparelhos Ideológicos de Estado funcionam de um modo massivamente prevalente pela ideologia, embora funcionando secundariamente pela repressão, mesmo que no limite, mas apenas no limite, esta seja bastante atenuada, dissimulada e até simbólica. (ALTHUSSER, 1974, p. 46-47, grifo do autor).

Com relação à cultura indígena, que durante o processo de catequização foi se perdendo, podemos perceber também uma versão distinta nos dois veículos (jornal e site) analisados. O site Portal das Missões apresenta em seus textos um modo de dominação cultural pacífica, como se o povo indígena estivesse sendo salvo dos pecados ${ }^{12}$ cometidos, como é possível observar no recorte:

R5I5: "O choque cultural foi um verdadeiro abismo a ser encarado. Os Jesuítas, cor da pele diferente, vinham falando uma nova verdade, vestidos de preto e com o corpo coberto, introduziram o "pecado" e a "vergonha", pregavam uma mudança de costume que nega a origem natural dos Guaranis." (Disponível em:

\footnotetext{
${ }^{12}$ Cabe pontuar que a ideia de pecado foi imposta pela Igreja Católica, como um meio de punir pessoas que não agiam conforme suas normas.
} 
http://www.portaldasmissoes.com.br/site/view/id/1791/lenda-cerro-doinhacurutum.html. Acesso em 30/03/2018, grifo nosso)

O choque cultural sofrido pelos indígenas ao se verem, de uma hora para outra, forçados a mudar seus costumes e crenças, reflete até hoje onde antes eram os 7 Povos das Missões, como destacado no recorte retirado do jornal Os Nheçuanos:

R9N5: "Índios guaranis, descendentes das reduções jesuíticas dos séculos 17 e 18, sobrevivem de vender réplicas das ruínas de suas cidades em São Miguel, Rio Grande do Sul, morando precariamente nos arredores da cidade. O tempo passou, mas a justiça não." (SAKAMOTO, Edição 31, 2016, grifo nosso)

Com isso, podemos perceber que até os dias atuais refletem as ações de dominação linguística, religiosa e cultural nos descendentes dos indígenas, os quais lutaram para manter vivas as suas tradições. No jornal Os Nheçuanos, também é possível observar uma seção dedicada à língua guarani, quanto ao que entendemos como um meio de manter viva a cultura e a língua, que sofreram tentativas de silenciamento na época das reduções.

Este domínio linguístico e cultural, atrelado ao domínio religioso, produz um apagamento na história indígena, tornando institucionalizados os discursos que circulam apenas pelo viés religioso e pela ótica de que os jesuítas estariam, pacificamente, ensinando seus costumes e sua religião. Esta indução histórica à passividade, produz uma certa repulsa cultural na região (predominantemente católica), onde, como observado, até hoje o povo indígena sofre as consequências deste passado.

O fato de a história, considerada como oficial, não retratar outros personagens que também foram importantes, como Nheçu, mostra o efeito de um discurso dominante, ou seja, é um efeito ideológico que marca as relações de forças existentes em determinado contexto sócio-histórico e ideológico. Esse discurso dominante produz determinados efeitos, os quais constituem a memória institucionalizada na/da região das Missões-RS, e perpassa gerações causando um estranhamento ao falarmos de Nheçu, seu povo e seus feitos.

\section{CONSIDERAÇÕES FINAIS}

Assim, em nosso estudo, compreendemos como os discursos são afetados ideologicamente e marcados pelo esquecimento/silenciamento. Desse modo, procuramos, por meio dos discursos sobre, os quais organizam a memória em circulação na região das Missões, os efeitos de sentido que tais discursos produzem, os quais, para nós, colocam-se entre a memória cristalizada/institucionalizada sobre a história dessa região, a qual está vinculada ao efeito de uma ideologia dominante, e a memória discursiva, a qual é marcada pelo esquecimento, fazendo com que novos sentidos irrompam na discursividade. Ou seja, explicitamos como tais discursos dominantes 
produzem uma memória e história marcada pelo esquecimento, bem como um silenciamento linguístico e cultural, determinando as relações entre a ideologia dominante e os indígenas que marcaram a história da região das Missões-RS.

Como foi possível observar durante nossas considerações analíticas, os discursos sobre que circulam na região das Missões trazem consigo a memória institucionalizada contando a história sobre o viés do vencedor ${ }^{13}$ e apagando as versões outras, as quais trazem os fatos contados a partir de um outro olhar. Trata-se de uma versão sobre os fatos.

Considerando que a história é sempre contada através de um determinado viés e esse viés adotado sofre ação direta da ideologia e da formação discursiva do sujeito que a enuncia, podemos considerar que independentemente do modo que é dito sobre a região das Missões, não há, de fato, uma verdade irrefutável, mas, sim, alguns discursos dominantes, cristalizados neste determinado contexto sócio-histórico que se sobressaem sob outros discursos.

Portanto, o trabalho e a discussão dos discursos em circulação na região das Missões-RS mostram o denominador comum que se pode observar em diferentes lugares aqui no Brasil: um discurso dominante, retratando uma história tida como oficial, cristalizando sentidos por meio de uma memória institucionalizada, esquecendo, de certa forma, personagens que foram tão importantes quanto os padres jesuítas, missionários e indígenas que receberam destaque, como o já referido Sepé Tiarajú. Não se pode esquecer, deve-se lembrar e buscar retratar as mais variadas versões para os fatos e dados ocorridos.

\section{REFERÊNCIAS}

ALTHUSSER, Louis. Ideologia e aparelhos ideológicos do estado. Lisboa: Editorial Presença, 1974.

CATEN, Odécio Ten. Opção Religiosa de Nheçu: pajé ou padre (jesuíta)?. In: O Nheçuano. Roque Gonzales, n. 5, p. 3, set./out. 2010.

COURTINE, Jean-Jacques. Análise do discurso político: o discurso comunista endereçado aos cristãos. São Paulo: EdUFSCar, 2009.

GRIGOLETTO, Evandra. Sob o rótulo do novo, a presença do velho. Porto Alegre: Editora da UFRGS, 2003.

HENRY, Paul. A história não existe? In: ORLANDI, Eni P. (org.). Et al. Gestos de leitura: da história no discurso. 4. ed. São Paulo: Editora da Unicamp, 2014.

\footnotetext{
${ }^{13} \mathrm{O}$ vencedor das lutas travadas no período jesuítico só será conhecido ao término da guerra Guaranítica, onde os povos indígenas foram dizimados pelo homem branco (entende-se aqui homem branco por jesuítas e bandeirantes), que ficaram com seu espaço e, muito mais que isso, com sua história, não abrindo espaço para uma discussão clara e concisa dos acontecimentos daquela época.
} 
INDURSKY, Freda. O trabalho discursivo do sujeito entre o memorável e a deriva. Signo e Seña, Buenos Aires, n. 24, p. 91-104, dez. 2013a.

INDURSKY, Freda. A emergência do sujeito desejante no discurso do MST. Gragoatá, Niterói, n. 34, p. 27-38, 1. sem, 2013b.

INDURSKY, Freda. Formação discursiva: ela ainda merece que lutemos por ela? In: SEMINÁRIO DE ESTUDOS EM ANÁLISE DO DISCURSO-SEAD, 2, p. 1-11, 2005. Porto Alegre. Anais eletrônicos [...] Porto Alegre: UFRGS, 2005. Disponível em:

http://anaisdosead.com.br/sead2_simposios.html. Acesso em: 21 maio 2018.

NEDEL, Ruy. Esta terra teve dono. 2. ed. Santo Ângelo: Furi: LEDIX, 2010.

NEDEL, Ruy. A história é prisioneira da Política. In: O Nheçuano. Roque Gonzales, n. 1, p. 3, outubro/novembro/2009.

ORLANDI, Eni. Ler a cidade: o arquivo e a memória. In: ORLANDI, Eni. Para uma enciclopédia da cidade. Campinas, SP: Pontes, Labeurb/Unicamp, 2003.

ORLANDI, Eni. Discurso e texto: Formulação e circulação dos sentidos. 2. ed. Campinas, SP: Pontes, 2005.

ORLANDI, Eni. As formas do silêncio. 6. ed. Campinas: Editora da Unicamp, 2007.

ORLANDI, Eni. Introdução às ciências da linguagem: Discurso e textualidade. 2. ed. Campinas, SP: Pontes Editores, 2010.

ORLANDI, Eni. Análise de discurso: princípios e procedimentos. 12. ed. Campinas: Pontes Editores, 2015.

PÊCHEUX, Michel. Semântica e discurso: uma crítica à afirmação do óbvio. Campinas, SP: Editora da Unicamp, 2014.

PÊCHEUX, Michel. Papel da memória. In: ACHARD, Pierre et al. Papel da memória. 4. ed. Campinas: Pontes Editores, 2015.

PETRI, Verli. O funcionamento do movimento pendular próprio às análises discursivas na construção do "dispositivo experimental" da análise do discurso. In: PETRI, Verli; DIAS, Cristiane. Análise de discurso em perspectiva: teoria, método e análise. Santa Maria: Ed. Da UFSM, 2013.

SAKAMOTO, Leonardo. À sombra do passado. In: O Nheçuano. Roque Gonzales, n. 31, p. 3 , setembro/outubro/2016.

SAKAMOTO, Leonardo. À sombra do passado II. In: O Nheçuano. Roque Gonzales, n. 32, p. 3, dezembro/2017.

SCHNEIDERS, Caroline M. Serafim da Silva Neto: entre a constituição e a circulação do conhecimento linguístico. 2014. Tese (Doutorado) - Universidade Federal de Santa Maria, Programa de Pós-Graduação em Letras, Santa Maria, 2014. 
SCHERER, Amanda Eloina; TASCHETTO, Tania Regina. O papel da memória ou a memória do papel de Pêcheux para os estudos linguístico-discursivos. Estudos da Lingua(gem), Vitória da Conquista, n. 1, p. 119-123, junho/2005.

TAVARES, Elaine. Padre Roque e Nheçu - Uma outra história. In: O Nheçuano. Roque Gonzales, n. 15, p. 11, nov./dez. 2012.

VALENZUELLA, Tainá S. Análise das missões jesuíticas do Rio Grande do Sul nos livros didáticos. Revista Latino-Americana de História, v. 2, n-6, p. 311-330, ago. 2013.

VENTURINI, Maria Cleci. Imaginário urbano: espaço de rememoração/comemoração. Passo Fundo: Ed. Universidade de Passo Fundo, 2009. 